\title{
Medsat: A Satellite System for Surveillance of Tropical Vector-borne Diseases
}

\author{
Byron Wood ${ }^{1}$, John Vesecky², Jim Lawless ${ }^{3}$, Louisa Beck ${ }^{1}$ \\ and Joan Salute ${ }^{3}$ \\ 1 TGS Technology Inc. \\ NASA Ames Rescarch Center MS 242-4 \\ Mofretl Ficld, CA 94035
}

2 Department of Atmospheric, Occanic and Space Sciences

University of Michigan

Ann Arbor, MI 48109

3 National Acronautics and Space Administration

Ames Research Center MS 242-4

Moffett Ficld, CA 94035

\begin{abstract}
In this paper, the authors describe the need for, and preliminary student design of, a research satellite system (Medsat) devoted to the surveillance of environmental and epidemiological factors that influence the patterns and dynamics of tropical vector-borne diseases.
\end{abstract}

At present, over half the earth's population is at risk to one or more tropical vector-borne diseases such as malaria, schistosomiasis, African sleeping sickness, or river blindness. Previous studies suggest that remote sensing data may provide a valuable tool for the characterization of key environmental and epidemiological factors that influence the distribution and dynamics of these diseases. However, in most areas these factors change at a temporal and spatial scale that current remote sensing systems are not designed to monitor. The spectral and spatial resolution of current operational systems, frequency of data acquisition, delays in data turn-around, and inability to acquire imagery over many tropical areas due to persistent cloud cover remain obstacles to the application of remote sensing data to the surveillance of tropical vector-borne diseases.

To address these issues, scientists from the National Aeronautics and Space Administration's Ames Research Center joined with faculty from the University of Michigan's Department of Atmospheric, Oceanic, and Space Sciences to sponsor a course to design a research satellite system (Medsat) devoted specifically to the surveillance of tropical vector-borne diseases. The course was organized to foster an 
interdisciplinary approach involving collaborations between students and researchers from engineering, natural resources, biology and public health. Design constraints specified that the Medsat system include visible/near-infrared and synthetic aperture radar sensors, provide frequent coverage of the Tropics, real-time data turn-around to researchers, and be launched by a Pegasus vehicle. Students in the course, however, went beyond just the design of the Medsat platform and sensor packages to include end-to-end considerations of data reduction, transmission and ground processing.

The final Medsat design called for the 340-kilogram satellite to be placed into a 210 equatorial orbit at 477 kilometers altitude, with an orbit time of 94.1 minutes and an anticipated life of four years. The platform was designed to carry two primary sensors, a four-channel visible/near-infrared "push broom" scanner, and a dual polarization L-Band synthetic aperture radar. Both sensors would operate at an off-nadir viewing angle of $15^{\circ}$, with a spatial resolution of 50 meters and a nominal scene size of $50 \times 50$ kilometers. To reduce the onboard resources required for data storage and downlinking, a data compression algorithm and optical storage disk was incorporated into the design. In addition to direct downlinking to specific study sites within two to four orbits of acquisition, the design included a control station in Hawaii from which flight commands could be transmitted and image data received.

The overall Medsat system design also included the development of small mobile ground stations that could be moved among study sites. Each station would be capable of receiving data directly from the satellite, and have capabilities for data decompression, image rectification, and integration into a geographic information system for analysis and modeling. The final course report describing the Medsat design has received favorable reviews by professional aerospace engineers and now provides the basis for further NASA studies into the design of a Medsat satellite system. 